\title{
A Study of Scanning Electron Microscope of Vancomycin Resistant Enterococcus faecalis from Clinical Isolates
}

\author{
Ajay Kumar Oli $^{1}$, Raju Sungar ${ }^{2}$, Nagaveni Shivshetty ${ }^{1}$, Rajeshwari Hosamani ${ }^{1}$, \\ Kelmani Chandrakanth Revansiddappa ${ }^{1^{*}}$ \\ ${ }^{1}$ Department of Biotechnology, Gulbarga University, Gulbarga, India \\ ${ }^{2}$ ELLA Foundation, Hyderabad, India \\ Email: ${ }^{*}$ ckelmani@gmail.com
}

Received February 4, 2012; revised March 2, 2012; accepted April 5, 2012

\begin{abstract}
Vancomycin-resistant Enterococcus faecalis pose an emerging health risk, but little is known about the precise epidemiology for vancomycin resistance. The glycopeptide resistant was studied using different techniques such as broth macrodilution, agar dilution combined with agar diffusion, morphology cell changes by scanning electron microscopy. Eight VREF isolated from different clinical samples were used. Results showed low level and high level resistant to vancomycin antibiotic at concentration of 64 to $128 \mu \mathrm{g} / \mathrm{ml}$, but antibacterial activity was reduced to $256 \mu \mathrm{g} / \mathrm{ml}$, the SEM revaled increased in the cell size with the antibiotic compared to control and standard culture. The technique constitutes simple method for the detection of organism.
\end{abstract}

Keywords: VREF; SEM; Vancomycin

\section{Introduction}

Enterococcus spp. are natural inhabitants of the gastrointestinal tract of humans and animals $[1,2]$ but can be also found in soil, water, and vegetables [3]. The two most important species, Enterococcus faecium and E. faecalis, are most frequently implicated in human and animal infections [4]. E. faecalis is an opportunistic pathogen known to cause serious infections, such as bacteraemia, septicaemia, urinary tract infections, wound infections, meningitis, and endocarditis $[2,5,6]$.

Prior to 1990 s, enterococci also have been recognized as an important cause of bacterial endocarditis for almost a century [7]. However, during the past decade, there has been a worldwide trend in increasing occurrence of enterococci (in the hospitals), a shift in the spectrum of enterococcal infections, and emergence of antimicrobial resistance among such isolates. Enterococci were reported as the second most common cause of nosocomial infections in the US. The most frequent infections caused by enterococci are urinary tract infections (UTIs) [8].

The acquisition of high level aminoglycoside resistance (HLAR) and vancomycin resistance has limited the therapeutic options available for clinicians. The transfer potential of vancomycin resistant genes from Enterococci to $S$. aureus have been reported in clinical settings, increases the importance of findings ways to limit the

${ }^{*}$ Corresponding author. spread of vancomycin resistant Enterococci (VRE) [9]. The problem of nosocomial enterococcal infection is compounded by emerging antibiotic resistance. The resistance alone does not explain the increase of Enterococci in nosocomial infections, microorganisms can adapt to different organic substances and other forms of environmental stress by several adaptive mechanisms. The exposure of bacteria to sub-MICs (Minimum Inhibition Concentration) of Vancomycin results in a significant alteration of cellular morphology and disturbance of metabolic activity in resistant $E$. faecalis [10]. The major adaptive responses of microorganisms to externally occurring changes in the environment are modifications of the cell envelope [11] and also coupled with changes in the overall morphology of the cells.

Scanning electron microscopy offers the unique ability to examine surface structures at relatively high resolution and proves particularly useful in the examination of the effect of antibiotics that act on the bacterial cell wall [1214]. The present study describes the effect of antibiotic stress on the morphology of vancomycin resistant $E$. faecalis strains examined by scanning electron microscopy.

\section{Materials and Method}

\subsection{Bacterial Strains}

The E. faecalis strains used in the present investigation were isolated from clinical samples over six months pe- 
riod from September 2008 and January 2009 from District Govt. hospital and diagnostic centres from Gulbarga region. The strains were isolated from blood, urine, pus and Cerebrospinal fluid sample.

Bacteria were isolated as previously described [15] and routinely grown in trypticase soy broth or agar at $37^{\circ} \mathrm{C}$. They were purified by standard methods and identified to the species level by the conventional biochemical identification scheme of De Marques and Suzart [16]. Confirmed isolates were stored in trypticase soy broth containing $20 \%$ glycerol at $-80^{\circ} \mathrm{C}$ until further characterisation could be performed.

\subsection{Antimicrobial Susceptibility Testing}

Antimicrobial susceptibility testing was performed on Mueller Hinton agar (Hi-media, India) by the standard disk diffusion method as recommended by the National Committee for Clinical Laboratory Standards [17]. The antibiotics used for the tests were vancomycin, ampicillin, oxacillin, rifamycin, ciprofloxacin, tobramycin, gentamycin, teicoplanin and streptomycin.

\subsection{Minimal Inhibitory Concentration (MIC)}

All strains were screened for vancomycin (Sigma Aldrich Ltd., Bangalore) MICs by the agar dilution method while the disc diffusion method was performed for screening susceptibility to other antimicrobials, by CLSI guidelines [18] E. faecalis NCIM 5025 used as control.

\subsection{Scanning Electron Microscopy}

SEM is used to examine the minor changes in cell morphology of the populations that have adapted to antibiotic stress [19]. The selected VREF strains were grown in BHI media with increasing vancomycin concentrations as described earlier. The bacterial cells from each culture were recovered by centrifugation at $6000 \mathrm{rev} / \mathrm{min}$ and the cells were washed twice with potassium phosphate buffer (50 mM, pH 7.0). Bacterial cells were then fixed by immersing in $2.5 \%$ glutaraldehyde in potassium phosphate buffer $(50 \mathrm{mM}, \mathrm{pH} 7)$ for overnight at $4^{\circ} \mathrm{C}$. Then the specimens were washed twice with buffer and dehydrated by ethanol series (v/v) ranging from $30 \%, 40 \%$, $50 \%, 60 \%, 70 \%, 80 \%, 90 \%$ to $100 \%$ and stored in $100 \%$ ethanol. For SEM, the specimens were dried to critical point, coated with gold and examined with an S-200C scanning electron microscope. [20] compared with standard NCIM 5025 and control EF122 strain.

\section{Results}

\subsection{Bacterial Isolates}

A total of 122 Enterococcus strains were isolated from different clinical samples on bile esculin agar. The species identities of the clinical Enterococccal isolates, includes 76 (62.29\%) strains were E. faecalis. The E. faecalis was the predominant isolates from urine, pus, CSF and blood samples.

\subsection{Antimicrobial Susceptibility}

E. faecalis strains showed resistance to the different antibiotics like vancomycin $(77.63 \%)$, gentamycin $(64.47 \%)$ and oxacillin (55.26\%) antibiotics, and were found to be multi drug resistant. The isolates were found susceptible to rifamycin $(61.84 \%)$, teicoplanin $(55.26 \%)$ streptomy$\operatorname{cin}(52.63 \%)$ and tobramycin $(51.13 \%)$.

\subsection{MIC's in E. faecalis Isolates}

All the vancomycin resistant E. faecalis were subjected for vancomycin MIC's test. Twelve strains showing drug resistance to all the antibiotics tested were selected for the MIC studies. Among them, 8 strains showed MIC in the range of $\geq 64 \mu \mathrm{g} / \mathrm{ml}$ while other 4 strains exhibited MIC of $\geq 128 \mu \mathrm{g} / \mathrm{ml}$. The bactericidal activity was observed at concentration of $256 / 256 \mu \mathrm{g} / \mathrm{ml}$ and low bactericidal growth at $128 / 256 \mu \mathrm{g} / \mathrm{ml}$. The concentration of antibiotic showed bacterial growth to about ten-fold at 24 hrs, with a concentration of $128 / 256 \mu \mathrm{g} / \mathrm{ml}$. An increase in 100 fold at $24 \mathrm{hr}$ was observed with a vancomycin concentration of $6 / 32 \mu \mathrm{g} / \mathrm{ml}$.

\subsection{Scanning Electron Microscope Study}

The results of cell morphology of VREF strains examined by scanning electron microscopy (SEM) revealed that in the presence of vancomycin, the cells altered their morphology with respect to different concentrations of the antibiotic. In the absence of vancomycin the cell morphology of control were apparently normal (Figure 1(a)). However standard culture showed no alteration in their cell morphology (Figure 1(b)) but enlarged, malformed and rough surfaced were observed in the antibiotic treated VREF culture with a concentration of 12 $\mu \mathrm{g} / \mathrm{ml}$ ) (Figure 1(c)).

\section{Discussion}

Enterococci infections have become increasingly common because of their intrinsic resistance to several antimicrobial agents and their propensity to acquire resistance from the environment [21]. Approximately $80 \%$ to $90 \%$ of all enterococcal infections are attributed to $E$. faecalis, whereas E. faecium is responsible for about $5 \%$ - $10 \%$ of these infections [22]. E. faecalis has recently evolved from a generally a virulent commensal into an MDT healthcare-associated pathogen causing difficult-to treat infections. Therefore, studies of E. faecalis resis 


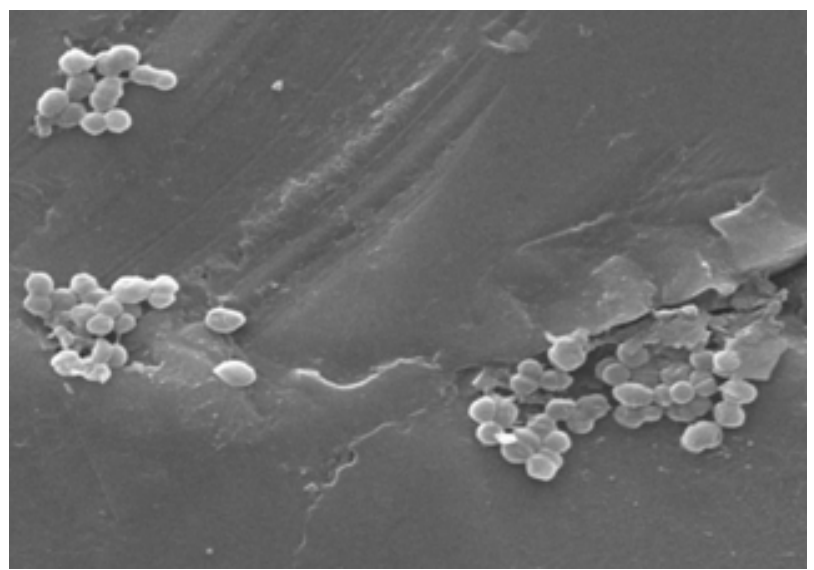

(a)

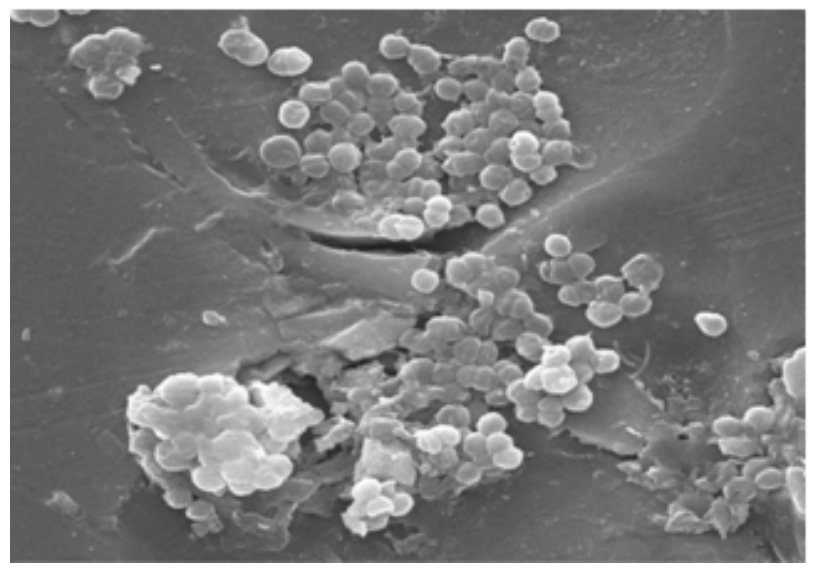

(b)

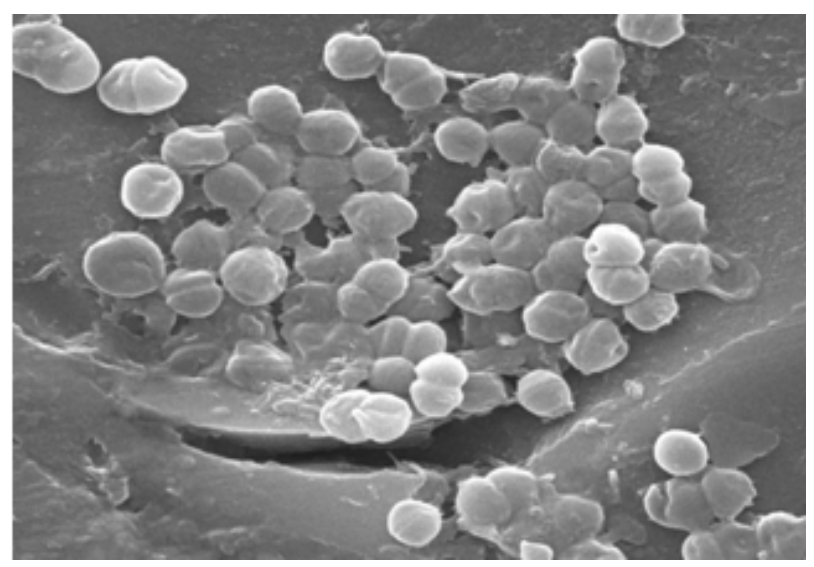

(c)

Figure 1. Scanning electron micrographs of VREF cells Magnification at 10,000 $\times 5 \mu \mathrm{m}$. (a) Control-strain EF 122 without antibiotic; (b) Standard culture NCIM 5025; (c) Strain EF 122 treated with antibiotic concentration of $12 \mu \mathrm{g} / \mathrm{ml}$.

tance have increased. Determination of glycopeptides activity has a significant role in guiding antibiotic usage. The results of this study confirms that E. faecalis were more resistant to the vancomycin $(77.63 \%)$, gentamycin $(64.47 \%)$ and oxacillin $(55.26 \%)$ and were sensitive to rifamycin $(61.84 \%)$, teicoplanin $(55.26 \%)$ and streptomycin $(52.63 \%)$ The multidrug-resistant Enterococci are being increasingly reported from all over world. Many studies have demonstrated that E. faecium is comparatively mores resistant than E. faecalis. [14]. The E. faecalis isolates investigated demonstrated resistance to vancomycin (MICs, 32 to 64, uglml). Similarly, Uttely et al. [23] reported prevalence of enterococci isolates resistant to both vancomycin and teicoplanin, and the vancomycin MICs were $>64 \mu \mathrm{g} / \mathrm{ml}$. The E. faecalis strain reported by shales et al. [24] had vanocmyin and teicoplanin MICs of 256 and $16 \mu \mathrm{g} / \mathrm{ml}$, respectively. In our studies MIC's for vancomycin among $12 \mathrm{E}$. faecalis strains 8 strains as showed $\geq 64 \mu \mathrm{g} / \mathrm{ml}$ and 4 strains had MIC of $\geq 128 \mu \mathrm{g} / \mathrm{ml}$. The bactericidal activity was observed at concentration of $256 / 256 \mu \mathrm{g} / \mathrm{ml}$ and low bactericidal growth at $128 / 256 \mu \mathrm{g} / \mathrm{ml}$. The concentration of antibiotic showed bacterial growth of about 10-fold at 24 hrs, of 128/256.

Morphological changes of organisms under stressful conditions are the most visible parameters of bacterial adaptation. The changes in morphology as an adaptive response to adverse environmental conditions have already been reported with several bacterial species [2527]. In our study the cell morphology of vancomycin treated cells of E. faecalis under SEM provided strong evidence that the presence concentration of Vancomycin is stressful for the bacterial populations, characterized by the large size. The increase in cell size reduces the relative contact surface and consequently reduces the attachable surface for organic (antibiotic) compounds. Therefore, bigger cells can tolerate the stress conditions better than normal cells of the same species.

Our study reveals that bacteria have evolved an adaptive response to the antibiotic stress and have developed drug resistance. This would be an alarming situation as Vancomycin is one of the few drugs used to treat patients with Enterococcus infection.

\section{REFERENCES}

[1] R. Creti, M. Imperi, L. Bertuccini, F. Fabretti, G. Orefici, D. R. Rosa and L. Baldassarri, "Survey for Virulence Determinants among Enterococcus faecalis Isolated from Different Sources," Journal of Medical Microbiology, Vol. 53, No. 1, 2004, pp. 13-20. doi: $10.1099 / \mathrm{jmm} .0 .05353-0$

[2] E. B. De Marques and S. Suzart, "Occurrence of Virulence-Associated Genes in Clinical Enterococcus faecalis Strains Isolated in Londrina, Brazil," Journal of Medical Microbiology, Vol. 53, No. 11, 2004, pp. 1069-1073. doi:10.1099/jmm.0.45654-0

[3] M. J. G. Burgos, R. L. Lopez, H. Abriouel, N. B. Omar and A. Galvez, "Multilocus Sequence Typing of Enterococcus faecalis from Vegetable Foods Reveals Two New 
Sequence Types," Foodborne Pathogens and Disease, Vol. 6, No. 3, 2009, pp. 321-327. doi:10.1089/fpd.2008.0169

[4] A. Aakra, H. Vebø, L. Snipen, H. Hirt, A. Aastveit, V. Kapur, G. Dunny, B. Murray and I. F. Nes, "Transcriptional Response of Enterococcus faecalis V583 to Erythromycin," Antimicrobial Agents and Chemotherapy, Vol. 49, No. 6, 2005. pp. 2246-2259. doi:10.1128/AAC.49.6.2246-2259.2005

[5] A. Giacometti, O. Cirioni, A. M. Schimizzi, M. S. Del Prete, F. Barchiesi, M. M. D'errico, E. Petrelli and G. Scalise, "Epidemiology and Microbiology of Surgical Wound Infections," Journal of Medical Microbiology, Vol. 38, No. 2, 2000, pp. 918-922.

[6] A. Hällgren, C. Claesson, B. Saeedi, H.-J. Isaksson, H. Hanberger and L. E. Nilsson, "Molecular Detection of Aggregation Substance, Enterococcal Surface Protein, and Cytolysin Genes and in Vitro Adhesion to Urinary Catheters of Enterococcus faecalis and E. faecium of Clinical Origin," International Journal of Medical Microbiology, Vol. 299, No. 5, 2009, pp. 323-332. doi:10.1128/AAC.49.6.2246-2259.2005

[7] D. R. Schaberg, D. H. Culver and R. P. Gaynes, "Major Trends in the Microbial Etiology of Nosocomial Infection," The American Journal of Medicine, Vol. 91, No. 3, 1991, pp. 72S-75S. doi:10.1016/0002-9343(91)90346-Y

[8] D. E. Low, N. Keller and A. Barth, R. N. Jones, "Clinical Prevalence, Antimicrobial Susceptibility, and Geographic Resistance Patterns of Enterococci: Results from the SENTRY Antimicrobial Surveillance Program, 1997-1999," Clinical Infectious Diseases, Vol. 32, Suppl. 2, 2001, pp. S133-S145.

[9] S. Mohanty, S. Jose, R. Singhal, S. Sood, B. Dhawan, B. K. Das, et al., "Species Prevalence and Antimicrobial Susceptibility of Enterococci Isolated in a Tertiary Care Hospital of North India," Southeast Asian Journal of Tropical Medicine and Public Health, Vol. 36, No. 4, 2005, pp. 962-965.

[10] L. V. Thomas and J. W. T. Wimpenny, "Investigation of the Effect of Combined Variations in Temperature, $\mathrm{pH}$ and $\mathrm{NaCl}$ Concentrations on Nisin Inhibition of Listeria monocytogenes and Staphylococcus aureus," Applied and Environmental Microbiology, Vol. 62, No. 3, 1996, pp. 2006-2012.

[11] H. J. Heipieper, F. J. Weber, J. Sikkema, H. Keweloh and J. A. M. de Bont, "Mechanism Behind Resistance of Whole Cells to Toxic Organic Solvents," Trends in Biotechnology, Vol. 12, No. 10, 1993, pp. 409-415. doi:10.1016/0167-7799(94)90029-9

[12] D. Greenwood and F. O'Grady, “Antibiotic-Induced Surface Changes in Microorganisms Demonstrated by Scanning Electron Microscopy," Science, Vol. 163, No. 3871, 1969, pp. 1076-1078. doi:10.1126/science.163.3871.1076

[13] D. Greenwood and F. O'Grady, "Scanning Electron Microscopy of Staphylococcus aureus Exposed to Some Common Anti-Staphylococcal Agents," Journal of General Microbiology, Vol. 70, No. 2, 1972, pp. 263-270.

[14] T. S. J. Elliott and D. Greenwood, "The Response of Pseudomonas aeruginosa to Azlocillin, Ticarcillin and Cefsu- lodin," Journal of General Microbiology, Vol. 16, No. 3, 1983, pp. 351-362. doi:10.1099/00222615-16-3-351

[15] C. R. Jackson, P. J. Fedorka-Cray, J. B. Barrett and S. R. Ladely, "Effects of Tylosin Use on Erythromycin Resistance in Enterococci Isolated from Swine," Applied and Environmental Microbiology, Vol. 70, No. 7, 2004, pp. 4205-4210. doi:10.1128/AEM.70.7.4205-4210.2004

[16] E. B. De Marques, S. Suzart, "Occurrence of VirulenceAssociated Genes in Clinical Enterococcus faecalis Strains Isolated in Londrina, Brazil," Journal of Medical Microbiology, Vol. 53, No. 11, 2004, pp. 1069-1073. doi:10.1099/jmm.0.45654-0

[17] National Committee for Clinical Laboratory Standards, "Performance Standards for Antimicrobial Disk Susceptibility Testing," Twelfth Informational Supplement (M100S12), ACCLS, Wayne, 2002.

[18] Clinical and Laboratory Standards Institute, "M07-A.B. Methods for Dilution Antimicrobial Susceptility Tests for Bacteria that Grow Aerobically; Approved Standard: 8th Edition," CLSI, Wayne, 2009.

[19] F. Lanzarini, "Effect of Teicoplanin and Vancomycin on Staphylococcus Ultrastructure," Microbiologica, Vol. 13, 1990, pp. 231-237.

[20] S. Raju, G. Rao, S. A. Patil and C. R. Kelmani, "Increase in Cell Size and Acid Tolerance Reponse in a StepwiseAdapted Methicillin Resistant Staphylococcus aureus Mutant," World Journal of Microbiology and Biotechnology, Vol. 23, No. 9, 2007, pp. 1227-1232. doi:10.1007/s11274-007-9352-4

[21] I. Dupre, S. Zanetti, A. M. Schito, G. Fadda and L. A. Sechi, "Incidence of Virulence Determinants in Clinical Enterococcus faecium and Enterococcus faecalis Isolates Collected in Sardinia (Italy)," Journal of Medical Microbiology, Vol. 52, No. 6, 2003, pp. 491-498. doi: $10.1099 / \mathrm{jmm} .0 .05038-0$

[22] A. H. C. Uttley, C. H. Collins, J. Naidou and R. C. George, "Vancomycin-Resistant Enterococci," The Lancet, Vol. 331 , No. 8575 , 1988 , pp. 57-58. doi:10.1016/S0140-6736(88)91037-9

[23] D. M. Shales, A. Bouvet, C. Devine, J. H. Shales, S. AlObeid and R. Williamson, "Inducible, Transferable Resistance to Vancomycin in Enterococcus faecalis A256," Antimicrobial Agents and Chemotherapy, Vol. 33, No. 2, 1989, pp. 198-203.

[24] M. O. Clements and S. J. Foster, "Stress Resistance in Staphylococcus aureus," Trends in Microbiology, Vol. 7, No. 11, 1999, pp. 458-462. doi:10.1016/S0966-842X(99)01607-8

[25] G. W. O'Hara and A. R. Glenn, "The Adaptive Acid Tolerance Response in Root Nodule Bacteria and Escherichia coli," Archives of Microbiology, Vol. 161, No. 4, 1994, pp. 286-292. doi:10.1007/BF00303582

[26] M. Ritz, J. L. Tholozan, M. Federighi and M. F. Pilet, "Morphological and Physiological Characterization of Listeria monocytogenes Subjected to High Hydrostatic Pressure," Applied and Environmental Microbiology, Vol. 67, No. 5, 2001, pp. 2240-2247. doi:10.1128/AEM.67.5.2240-2247.2001 
[27] G. Neumann, Y. Veeranagouda, T. B. Karegoudar, O. Sahin, I. Mausezahl, N. Kabelitz, U. Kappelmeyer and H. J. Heipieper, "Cells of Pseudomonas putida and Entero- bacter sp. Adapt to Toxic Organic Compounds by Increasing Their Size," Extremophiles, Vol. 9, No. 2, 2005, pp. 163-168. doi:10.1007/s00792-005-0431-x 